\title{
Elas por elas: experiências docentes nos espaços escolares da educação básica, um estudo na literatura negra
}

\section{She by her: teaching experiences in the school spaces of basic education, a study in black literature}

Recebido: 08/07/2020 | Revisado: 13/01/2021 | Aceito: 01/02/2021 | Publicado: $17 / 05 / 2021$

Luzineide Vieira de Sousa

ORCID: https://orcid.org/0000-00018864-1782

Universidade do Estado da Bahia (UNEB)

E-mail: Ivsousa@uneb.br

Como citar: SOUSA, L. V.; Elas por elas: experiências docentes nos espaços escolares da educação básica, um estudo na literatura negra. Revista Brasileira da Educação Profissional e Tecnológica, [S.I.], v. 1, n. 20, p. e10907, maio. 2021. ISSN 2447-1801.

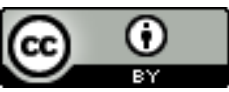

This work is licensed under a $\underline{\text { Creative }}$ Commons Attribution 4.0 Unported License.

\section{Resumo}

O texto é resultado obtido da experiência do Estágio Supervisionado I do Curso de Letras Vernáculas do Departamento de Ciências Humanas, Jacobina-Bahia, como possibilidade de reflexão e construção de atitude pedagógica na formação de professor-pesquisador e na articulação do ensino com a extensão. Por esta atitude pedagógica buscamos destacar uma atividade significativa de análise, de que forma os estudantes/estagiários e da rede básica de ensino, refletem e analisam posturas racistas em territórios da educação formal. O estudo investigativo inspirou-se em Djamila Ribeiro, Carla Akotirene, Sílvio Almeida, Suely Carneiro, Adilson Moreira, bell hooks e Elizandra Souza. Através da leitura de escritos das escritoras negras, os debates sobre o racismo tem sido ampliado, afim de acabar qualquer atitude de discriminação racial nos territórios escolares, as interseccionalidades e afetamentos que provocam e atravessam os sujeitos estagiários, estudantes da rede básica de ensino e docente do estágio participes do processo que ao analisar as posturas contra a discriminação racial dos estudantes, se indagam e puseram-se em análise e reflexão por meio da atitude pedagógica lançada à turma, em que os afetamentos junto com as estudantes se fizeram estudo e vida entrelaçados no conhecimento em rede.

Palavras-chave: Literatura negra. Estágio Supervisionado. Formação de professores/as.

\begin{abstract}
The text is the result of the experience of Supervised Internship I of the Course of Vernacular Letters of the Department of Human Sciences, Jacobina-Bahia, as a possibility of reflection and construction of pedagogical attitude in the formation of teacher-researcher and in the articulation of teaching with the extension. Through it we seek to highlight how students / interns and the basic education network reflect and analyze racist attitudes in formal education territory. The investigative study was inspired by Djamila Ribeiro, Carla Akotirene, Sílvio Almeida, Suely Carneiro, Adilson Moreira, bell hooks and Elizandra Souza. The activities in the internship, the intersectionalities and affects that provoke and cross the trainee subjects, students of the basic education network and internship teacher participate in the process that when analyzing the racist attitudes of the students, they also ask themselves and put themselves in analysis and reflection of the pedagogical attitudes launched to the class in which the affects along with the students were studied and life intertwined in the knowledge in a network.
\end{abstract}

Keywords: Black literature. Supervised internship. Teacher training. 


\section{INTRODUÇÃO}

O que você tem feito pela luta antirracista? Esta questão está no livro pequeno Manual Antirracista de Djamila Ribeiro(2019), discussão que conduz este tema e confere nosso ponta pé, para todo começo desse trabalho. Desta forma, como docente de uma Universidade pública baiana, com o comprometimento a favor dos estudantes do entorno do território do Piemonte da Chapada Diamantina, que se expande através dos dez municípios ligados a Jacobina-BA tem gerado um espaço de militância política nas atitudes pedagógicas docentes e dos estudantes, no sentido de engajamento em busca de alternativas na manutenção das suas atividades, respeitando as diferenças de condições e oportunizando uma educação que pensa na transformação social visando sujeitos e contextos mais humanizados.

Para bell hooks (2013, p.53-54), "nossas preferências políticas moldam nossa pedagogia do que com sua aceitação passiva de modos de ensinar e aprender que refletem parcialidades, particularmente o ponto de vista da supremacia branca". Esse pensamento torna-se potente porque coloca-nos em reflexão sobre a abordagem pedagógica que estamos assumindo nas nossas salas de aulas, qual o nosso compromisso para criar uma comunidade de aprendizagem que faça sentido para os alunos/as? Como nos diz bell hooks (2013), "É preciso instituir locais de formação onde os professores tenham a oportunidade de expressar seus temores e ao mesmo tempo aprender a criar estratégias para abordar a sala de aula e o currículo multiculturais".

Sabemos que somos resistentes a mudar nossos paradigmas, e precisamos de um contexto, conforme diz bell hooks (2013, p.54) "onde deem voz a seus medos, onde falem sobre o que estão fazendo, como estão fazendo e por quê?". Assim, espera-se com este estudo colocar em evidencias as atitudes pedagógicas vivenciadas por alunas/negras que ingressaram no Estágio Supervisionado, do curso de Letras Vernáculas, da Universidade do Estado da Bahia-UNEB.

Assim, é nossa militância em sala de aula, de propiciar discussões que possam contribuir para uma comunidade de ensino-aprendizagem central e significativa, que envolva nossos estudantes na sua formação inicial e, também, ocasione na prática o conhecimento crítico capaz de transformar atitudes racistas, estimular a reflexão sobre o conceito e levar ao estudante da educação básica, a conhecer mais sobre a temática, através da literatura negra.

\subsection{SOBRE AS INTERLOCUTORAS DO ESTUDO}

Este estudo contou com a construção colaborativa, incluindo a docente/pesquisadora, das 22 estudantes e do estudante de Letras Vernáculas e dos estudantes da Educação Básica de Jacobina-Bahia que constitui sujeitos objeto da pesquisa. Todas as estudantes do Estagio Supervisionado I puderam relatar/narrar 
suas experiências de vida e de trajetória acadêmica. Percebeu-se que as estudantes negras se escondiam, fingiam estar estudando, isso as vezes, durava a aula toda, nem mesmo sendo provocadas a falar, elas permaneciam em silêncio. Em raros momentos, se manifestavam, mas com certa indignação sobre estereótipos e estigmas sobre si, pelas atitudes docentes, que se apoiam numa matriz dominante, de não haver lugar de escuta para estas estudantes que permanecem caladas, principalmente nas disciplinas de formação e ensino.

Embora, essas questões estejam diretamente ligadas as minhas alunas negras, também propicia uma reflexão docente, para pensar como a sala de aula possa servir como meio para que atitudes pedagógicas alcancem os debates sobre a questão racial no Brasil? A fim de apresentar uma experiência de atitude pedagógica colaborativa para o debate, no que tange pensar de que lugar poderia depreender 0 conceito de racismo estruturante infiltrado nos espaços escolares?

Para tal, realizamos inicialmente reflexões sobre o conceito de racismo, apresentando-o conforme Almeida (2019, p.21), "o racismo fornece o sentido, a lógica e a tecnologia para a reprodução das formas de desigualdade e violência que moldam a vida social contemporânea". De tal acaso, outras formas de classificação são situações de parcialidade, e, consequentemente, incompletas de imaginar o racismo. Sendo assim, a escrita desse texto se fez por meio das experiências pedagógicas vivenciadas em sala de aula, tanto da docente, quanto das alunas/professoras em que estavam comprometidas em desvelar a face da opressão e dos preconceitos raciais. Notadamente, incluindo espaços de escuta para essas questões.

Assim, falar de atitudes racistas e Educação nos remetem a luta histórica dos negros no Brasil, por direitos e de oportunidades para homens e mulheres negras em diferentes parte do mundo. Neste cenário, ter acesso à educação escolarizada, a liberdade de expressão e ao mercado de trabalho construíram-se e ainda é uma luta permanente das reinvindicações, assim como o enfrentamento ao racismo e ao sexismo.

Nesse sentido, todo este cenário apresenta neste texto como linhas subjacentes que se entrecruzam e se extravasam como pulsão de vida e educação, pois nossas pesquisas com ensino e extensão são feitas de vida e cada vida nos importa. Para esta ação difícil, desafiadora, inacabada, é preciso que abandonemos os saberes fragmentados, verticalizados e horizontalizados e nos lancemos na aventura de educar tendo como centralidade as aprendizagens para nos arriscarmos a transitar por territórios de saber que exige de nós, leituras, anotações, ida e vindas, deslocamentos e abertura para enxergarmos a realidade que põe à amostra como unidade fragmentada, multidimensionada.

Conforte diz Paulo Freire(1997), "É fundamental diminuir a distância entre o que se diz e o que se faz, de tal forma que, num dado momento, a tua fala seja a tua prática". Quando iniciei as aulas do semestre 2019.2, com a turma do componente de Estágio Supervisionado I, do curso de Letras Vernáculas, presenciei na sala de aula, uma turma plural e daí resolvi fazer um mapeamento dos marcadores sociais que envolviam os/as estudantes. 
Figura 1: Turma do Estágio Supervisionado I, por sexo-curso de Letras Vernáculas, Campus IV-Jacobina 2019/2020

\begin{tabular}{|l|c|c|c|}
\hline \multicolumn{1}{|c|}{ Por idade } & $\mathbf{2 0}$ a 26anos & $\mathbf{2 7 - 3 3}$ anos & $\mathbf{3 4}$ anos \\
\hline Total & 17 & 5 & 1 \\
\hline Mulheres & $73,9 \%$ & $21,7 \%$ & \\
\hline Homens & & & $4,3 \%$ \\
\hline
\end{tabular}

Fonte: Arquivo de dados da docente, coordenadora do trabalho, por amostra da turma do Estagio Supervisionado I 2019.2 / 2020.1

Figura 2: Turma do Estágio Supervisionado I, por Raça/cor-negras e pardas, do curso de Letras Vernáculas, Campus IV-Jacobina

\begin{tabular}{|l|cc|}
\hline Por Raça/cor- & negras-pardas & brancas (se autodeclaram) \\
\hline Total & 19 & 4 \\
\hline Mulheres & $82,6 \%$ & $17, \%$ \\
\hline Homens & $1 \%$ & \\
\hline
\end{tabular}

Fonte: Arquivo de dados da docente, coordenadora do trabalho, por amostra da turma do Estagio Supervisionado I 2019.2 / 2020.1

Figura 3: Estudantes residentes em outras cidades, do curso de Letras Vernáculas, Campus IV-Jacobina

\begin{tabular}{|l|c|c|}
\hline Por residências & em outras cidades & Jacobina \\
\hline Total & 30 & 5 \\
\hline Mulheres & $100 \%$ & $80 \%$ \\
\hline Homens & & $20 \%$ \\
\hline
\end{tabular}

Fonte: Arquivo fotográfico da docente, coordenadora do trabalho, por amostra da turma do Estagio Supervisionado I 2019.2 / 2020.1 
Figura 4: mapeamento da turma do Estágio Supervisionado I, do curso de Letras Vernáculas, Campus IV, UNEB, Jacobina-Bahia

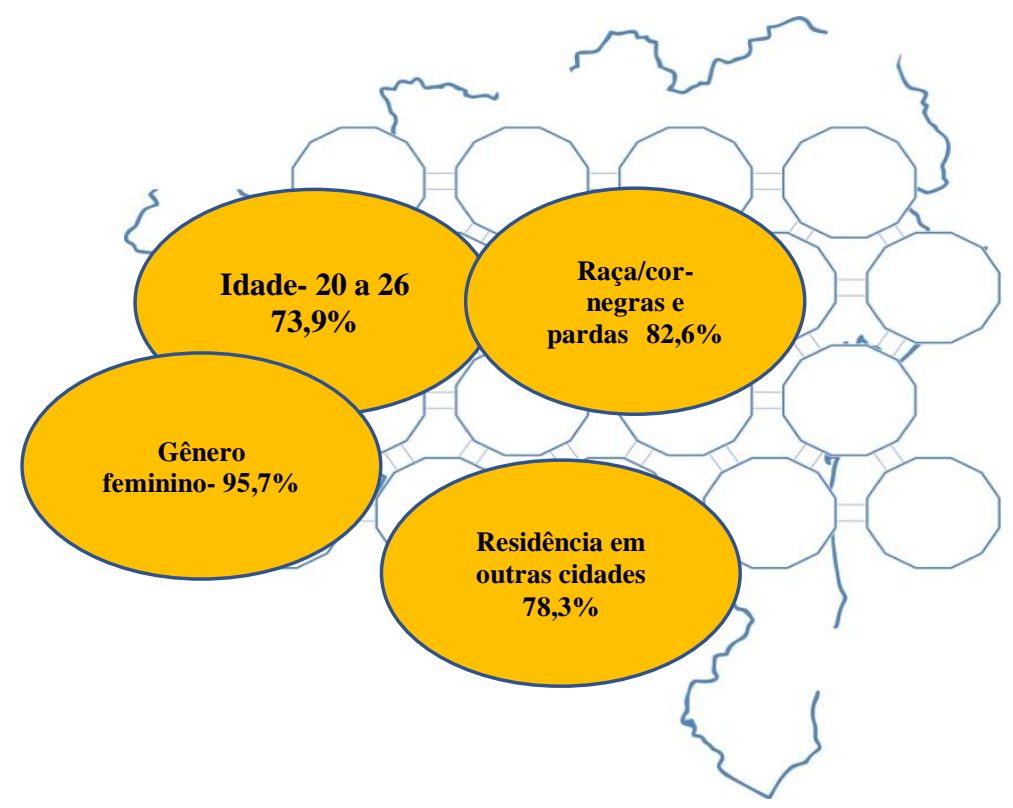

Fonte: SILVA, 2020

Das 23 alunas/professoras, 17 estão entre $20-27$ anos, perfazendo um total de 73,9\%; 05 estão entre $27-33$ anos, o que representa um total de $21,7 \%$ e apenas uma estudante acima de 34 anos, cujo percentual é de apenas 4,3\%. Esse registro ocasionou em sala de aula algumas discussões em torno da raça e gênero e que determinada por esses marcadores tem exposto o racismo aversivo, que segundo Adilson Moreira (2019), "segundo psicólogos cognitivistas, os sentimentos conscientes e inconscientes que sustentam atitudes negativas em relação a negros são ancorados pelo funcionamento do psiquismo humano". Desse modo, compreendemos que seria relevante trazer para o debate essa problemática.

Com esse percentual de 95,7\%, das 23 alunas/professoras, e apenas 01 homem, um percentual de apenas $4,3 \%$, o que nos possibilita inferir que embora saibamos que a atração pela carreira do magistério, é baixa, podemos vir a ter através desta turma um diferencial. Os dados oficiais do censo escolar são ratificados quanto à maioria das mulheres habitarem à docência e os territórios escolares. Os resultados do Censo para todos informaram que 2,3 milhões de professores e professoras atuavam na Educação Básica, destes, $63,8 \%$ são vinculados ao ensino fundamental. Os números evidenciam um protagonismo feminino, $80 \%$ dos docentes são do sexo feminino. (INEP, 2017).

Entretanto, não é somente esse dado que foi levantado, percebeu que nessa contemporaneidade, como vemos nas graduandas, futuras docentes, apresentam nas suas subjetividades de mulheres negras um percentual que revelam ao somarmos as que se auto declararam pardas e negras, o total foi de 19 alunas, cujo percentual é de $82,6 \%$. Apenas quatro se autodeclararam brancas, cujo percentual foi de apenas 
17,4\%. Neste aspecto, Soares (2008) traz como centralidade, a explicação de que 0 aumento do percentual de negros se deve a mudanças em como os indivíduos se percebem, e se enxergam racialmente. Ademais estes registros nos revelam que a Universidade do Estado da Bahia, de fato, inclui negros e negras no ensino superior, demarcando o quanto a representatividade importa e nos atravessa nas conexões interseccionadas de gênero e raça.

Sueli Carneiro, sobre a mulher negra, nos diz a respeito:

ser negro sem ser somente negro, ser mulher sem ser somente mulher, ser mulher negra sem ser somente mulher negra. Alcançar a igualdade de direitos é converter-se em um ser humano leno e cheio de possibilidades e oportunidades para além de sua condição de raça e de gênero. Esse é o sentido final dessa luta (2003, p.5).

Defendemos as subjetividades negras nas práticas pedagógicas nesse contexto atual, por que entendemos que a história contada sobre as mulheres negras estão contaminadas de racismo e sexismo, nos ambientes escolares. A não aceitação e o não conformismo por uma identidade que foi dada por imposição a categoria, tem levantado outros debates para além de raça e racismo. $E$, ninguém melhor do que os sujeitos que foram atravessados por seus marcadores de gênero, raça/cor, classe social, sexualidades, nos contextos de opressão, para tratar dos princípios de raça e racismo nos espaços escolares, por isso a imersão delas por elas.

Para Ribeiro(2019):

a importância de estudar autores negros não se baseia numa visão essencialista, ou seja, na crença de que devem ser lidos apenas por serem negros. A questão é que é irrealista que numa sociedade como a nossa, de maioria negra, somente um grupo domine a formulação do saber. É possível acreditar que pessoas negras não elaborem o mundo? É sobre isso que a escritora Chimamanda Ngozi Adichie alerta ao falar do perigo da história única. $\mathrm{O}$ privilégio social resulta no privilégio epistêmico, que deve ser confrontado para que a história não seja contada apenas pelo ponto de vista do poder. É danoso que, numa sociedade, as pessoas não conheçam a história dos povos que a construíram.

Isso não quer dizer que a entrada dessas alunas/professoras nesses territórios estruturantes, vai trazer uma mudança imediata, mas servirá como possibilidade de engajamentos de ideias novas sobre a mulher e o racismo. Esse risco é tentador, mais do que o apego e apoio aos modelos do sistema dominante.

Segundo bell hooks(2013): 
hoje em dia, quando a "diferença" é tema quente nos círculos progressistas, está na moda falar de "hibridização" e "cruzar fronteiras", mas raramente encontramos exemplos concretos de indivíduos que realmente ocupem posições diferentes dentro das estruturas e partilhem ideias entre si, mapeando seus terrenos, seus vínculos e suas preocupações comuns no que se refere às práticas de ensino.

Nesse sentido, essas questões se colocam diariamente, na nossa prática docente, pois negar a política do racismo, do sexismo, que determina o que ensinamos e como ensinamos é uma militância nossa e de nossos estudantes engajados na política da Universidade. Por essa política de engajamento entre docentes, estudantes e Universidade, assumimos uma proposta de trabalho com os estudantes da Educação Básica, de trabalhar com a literatura de escritoras negras como atividades extensionistas.

Assim, nossa proposta de trabalho teve início com reuniões pós-aulas, para traçarmos um planejamento das atividades pedagógicas com estudantes da Educação Básica nos espaços escolares jacobinenses. Dado os frutos dos nossos encontros resolvemos levar a leitura a partir das escritoras negras, que escolhemos trabalhar, para os espaços escolares da rede pública, mirando nas possibilidades de ensino-aprendizagem fecundas, cuja finalidade é estender esse debate para os espaços escolares com intuito de ampliar a discussão para alcançar outras mudanças de atitude sobre o racismo estruturante na educação escolar.

Debatemos assim, com Djamila Ribeiro, Carla Akotirene, Sueli Carneiro e Silvio Almeida (2019), o conceito do racismo o quanto incomoda a sociedade contemporânea brasileira, onde aflora discussões acaloradas e engajadas nos aspectos históricos, políticos, sociais, institucionais e jurídicos. Isso quer dizer que devemos militar contra o racismo nos espaços escolares, para ir construindo um conhecimento de desconstrução do pensamento propagado pela matriz dominante. Assim, nosso desafio foi lançado e resultou nessa proposta:

\section{QUE FIZEMOS, SÓ COMEÇAMOS...}

Das reuniões realizadas tiramos uma proposta de trabalho com escritoras negras, com a leitura e análises de suas obras, nos espaços da educação básica, catalisando os marcadores de gênero e raça com intuito de levar a consciência crítica dessa literatura negra e chamar a atenção para a questão do racismo não somente no olhar de raça e gênero, mas na percepção de tomada de postura que tem o dever de reparar nossos entendimentos sobre as características da mulher negra. Como diz Djamila Ribeiro(2019), "Afinal, o antirracismo é uma luta de todos/as, não devemos nos calar diante de tais posturas que somente favorece o racismo estruturante". 
Para organizar essas leituras de escritoras negras, fizemos um levantamento de suas produções em diversos gêneros textuais, e para começo de inspiração e mudança de atitude na contramão do racismo, escolhemos trabalhar com os poemas e depois os livros de diferentes escritoras negras, que iniciamos com a literatura belíssima de Elizandra Souza, mulher negra periférica, nascida na Zona Sul de São Paulo, 1983, influenciada pela cultura hip hop, que emerge nas periferias nos anos 1990, com formação na comunidade social, em que oferece uma possibilidade para discutirmos questões de identidade fixa e ocupação social da mulher negra, descontruindo imagens equivocadas, além de valorizar a voz feminina negra.

Para Djamila Ribeiro(2019):

o racismo é, portanto, um sistema de opressão que nega direitos, e não um simples ato da vontade de um indivíduo. Reconhecer o caráter estrutural do racismo pode ser paralisante. Afinal, como enfrentar um monstro tão grande? No entanto, não devemos nos intimidar. A prática antirracista é urgente e se dá nas atitudes mais cotidianas.

Se discutir o racismo pelas situações corriqueiras favorecerá mudanças de atitude, então estamos militando por essa abordagem libertadora. Talvez, os questionadores digam, mas isso, já acontece nos debates acadêmicos. É possível que sim, mas não tem aberto fendas para mostrar práticas antirracistas nos espaços escolares, além de valorizar essa literatura produzida por mulheres negras que tem afirmado uma política de libertação.

Assim, a leitura das escritoras negras se fez por diferentes vozes: a da professora/pesquisadora, das alunas/estagiárias negras, das vozes que se fazem presença das intersecções de nossas vozes, elas por elas. Com isso foi germinando o desabrochar das ideias, dos desejos e tomada de posturas, que se propagam nos espaços escolares, a partir dos nossos encontros mensais.

Dentro de uma estimativa, pensamos em levar para os espaços escolares quatro produções escritas de escritoras negras, para conferir um lugar de direito, por meio da literatura negra. Depois desse trabalho com a leitura das produções negras, nos espaços escolares, pensamos em reuniões virtuais (lives), com as respectivas escritoras, num debate de saberes e desenquadramentos de atitudes racistas.

Outro ponto importante em toda a obra de Djamila Ribeiro(2019), é sua escolha em usar epistemologicamente e apresentar às leitoras intelectuais negras para elaborar seus argumentos, trazendo obras de referência para a teoria feminista que fogem do contexto ocidental, branco e hegemônico. "Sim, esses discursos trazidos por essas autoras são contra hegemônicos no sentido de que visam desestabilizar a norma, mas igualmente são discursos potentes e bem construídos a partir de outros referenciais e geografias [...]". 
Sabemos bem, que a democracia racial no Brasil é puramente mito, visto que aos negros são dadas as piores oportunidades (isso quando são dadas), as balas perdidas, sobretudo nos bairros de maior vulnerabilidade social, coincidentemente, só encontram corpos negros, aquele que é visto como bandido é sempre o negro, como que podemos falar em democracia racial, como podemos falar que somos todos iguais e não somos vistos e tratados da mesma forma?

Esse trabalho cria um vínculo entre Universidade e escola, no intuito de desnormatizar o racismo impregnado nas atitudes das pessoas no espaço escolar. É importante que as pessoas brancas compreendam os mecanismos pelos quais 0 racismo opera, e ninguém melhor desse lugar de sofrimento da opressão, para discutir esse conceito.

Não se pode perder de vista que a questão da literatura negra nesse século XXI ganhou destaque, não apenas pela estética identitária, mas pela existência dessa mulher negra se colocando em visibilidade e politicamente. Nos escritos de Elizandra Souza o sentimento de se ver negra, ultrapassa as páginas redigidas no texto, pois evidencia a mulher negra exposta as atrocidades, de um sistema dominante, mas que por meio delas, conseguem superá-las e criar linhas de fuga para construção de sua subjetividade feminina e também da sua negritude.

Assim, para Djamila Ribeiro(2019), essas experiências vivenciadas por mulheres negras, torna-se seu lugar de fala, na apropriação do sentido para além do semântico da palavra, e na construção subjetiva de suas próprias percepções, de entender que é preciso desautorizar essa visão da matriz colonial que gera uma sociedade desigual, para trazer ao debate as identidades que foram impostas por esses contextos coloniais, já que são identidades que geram incômodos por razão dessas mulheres não se veem realmente na sua existência, tanto pela sua história de vida, quanto na sua subjetividade feminina.

Como diz Alcoff (2016 apud RIBEIRO, 2019),

- colonialismo cria e reifica identidades como meio de administrar povos e estabelecer hierarquias entre eles. Por isso, muitos acreditam que devemos postular como objetivo um futuro no qual as identidades criadas pelo colonialismo possam dissolver-se.

Nesse sentido, existe uma linhagem de mulheres negras fortes que, em vez de se lamentar, criam linhas de fuga por sua força militante e constituem novas subjetividades femininas, exemplo disso, é a potência e existência dessa mulher na literatura negra.

No caso do poema que veremos, nesse estudo, da Elizandra Souza, já aponta para essa desautorização de identidade imposta, já declara uma subjetivada de mulher negra para além do campo escurecido, parte do lugar epistemológico e assume uma autonomia de negritude, pelos versos produzidos no poema, em que 
instaura uma presença política que desfaz e contesta uma identidade atribuída ao morador da periferia como sujeito colonializado e moldado pelo sistema dominante.

Se há uma intenção de romper com a imagem da mulher negra exposta ao racismo do sistema colonial, as intelectuais já fazem isso, pois levam em conta a sua negritude nas diferenças, deixam seus gritos nas produções escritas e desconstroem uma imagem ligada ao corpo, saíram do nicho, voaram e resistiram pelos discursos que contestam, das segregações dadas a raça, ao gênero e classe.

Por isso, esse trabalho propôs dar visibilidade a presença da literatura negra dentro da literatura periférica e através da escrita da Elizandra Souza, mas, antes de fazermos esse trabalho nos espaços escolares, já tínhamos feito encontros para discutirmos as leituras e percepções sobre as produções das referidas escritoras negras escolhidas para o trabalho do ano de 2019.

O primeiro encontro no espaço escolar se deu com a leitura do poema de Elizandra Souza-Violação, composto por cinco estrofes e encontra-se no livro "Águas da Cabeça", nas páginas 68-69. Fizemos a leitura e depois a análise do texto com os alunos do $9^{\circ}$ Ano de três escolas públicas de Jacobina, no período de 19 à 20 de setembro de 2019, com o tempo de duas horas semanais. Apresentaremos a seguir as análises colaborativas e das discussões que presenciamos com movimentos de escuta, em que fizemos anotações, destacadas e organizadas a partir das análises feitas pelos alunos/as da série do 9Ano da Educação Básica.

\section{Violação}

Toca viola, toca viola... Arranca esse pedregulho

Esse mal-estar social

Essa democracia racial

Presa na minha garganta

Toca viola, toca vitrola

Gira a roleta e atira

Mata esse avesso racismo

Este isto, este aquilo

Viola esta concepção

Toca viola, toca vitrola

Troque este disco riscado

Cale este cantor engasgado

Estrangule o opressor

Encerre este espetáculo.

Toca viola, toca vitrola...

Despida dessa máscara branca

Dessa falsa dança

Do estupro nos crespos 


\author{
Deste modelo de mucama \\ Que não deito e nem te sirvo na cama \\ Toca viola, toca vitrola... \\ Porque já não me serve \\ Este arranhado disco! \\ (Águas da cabaça, p. 68, 69.)
}

\title{
3 NO LUGAR DE FALA, EXISTÊNCIA DE SI...
}

Na primeira estrofe a autora diz o seguinte: "[...] Arranca este pedregulho/ Esse mal-estar social/ Essa democracia racial/ Presa na minha garganta" (2-4). Percebe-se nessa estrofe a indignação e angústia em relação a uma sociedade racista. (Estudantes do 9ำ $\mathrm{Ano}^{1}$, análise, 2019).

$\mathrm{Na}$ segunda estrofe "[...] Mata esse avesso racismo/Este isto, este aquilo/Viola esta concepção, (2-3).

A autora fala sobre o quão ruim é viver nessa sociedade que exclui e marginaliza a pessoa negra, que tenta a todo custo inferiorizar essa pessoa. (Estudantes do 9ํㅡㄹ, análise, 2019).

$\mathrm{Na}$ terceira estrofe "[...]Troque este disco riscado/Cale este cantor engasgado/ Estrangule o opressor /Encerre este espetáculo, (3-2).

$A$ autora fala sobre a democracia racial, que é um termo utilizado por algumas pessoas que dizem que não existe racismo ou discriminação racial no Brasil. Como falado anteriormente, por muito tempo falaram em nome de outros, acredita-se que este disco riscado e este cantor engasgado, mencionados pela escritora, é nada mais nada menos que todos os rótulos submetidos à imagem da pessoa negra. Os versos seguintes remetem ao fim, ou pelo menos, ao desejo de que tudo isso acabe, todo o preconceito, racismo, toda forma de opressão, e que isso deixe de ser como uma peça de teatro, pois é assim que muitos enxergam o racismo, como lazer recreativo. (Alunas/Estagiárias e alunos/as do 9ํㅡㅅㅡ. análise, 2019).

Na quarta estrofe "[...] Despida dessa máscara branca/Dessa falsa dança/Do estupro nos crespos/Deste modelo de mucama/Que não deito e nem te sirvo na cama, (4-2).

A autora fala sobre os estupros ocorridos na época da escravidão, mas também de como o corpo da mulher negra é objetificado, de como, quando é para fazer crueldade a máscara branca cai (supõe-se que pessoas brancas são civilizadas, são constantemente associadas a anjos, por possuírem características angelicais, etc.). (Estudantes do 9o Ano, análise, 2019).

$\mathrm{Na}$ última estrofe, Elizandra Souza fala "[...] Porque já não me serve/ Este arranhado disco!", (5-2).

Isso significa que ainda que exista diversas narrativas acerca do negro, e sobretudo, da mulher negra, as narrativas negativas, na tentativa de marginalizar

\footnotetext{
${ }^{1}$ Por questões éticas e morais, assim como preservar a idade dos estudantes do 9o Ano com a pesquisa, optou-se por não utilizar nomes próprios, mas trazer a análise no coletivo.
} 
essas pessoas e consequentemente suas produções, não serão mais aceitas. (Alunas/estagiárias e Estudantes do 9ํAno, análise, 2019).

De fato, como observado nas respostas de análise do poema feita pelos estudantes/estagiárias e estudantes da educação básica percebeu-se que a maioria deles/as são negros/as, já conhecem o debate sobre o racismo, mas, que presenciam(ainda) algumas atitudes racistas e machistas. Isso vem reforçar a necessidade de mais estudo de inclusão dessa temática nas escolas da Educação Básica, incluindo mais leitoras-escritoras negras na proposta do trabalho do professor em sala de aula.

É perceptível e significativa o resultado do estudo pelo qual professora/pesquisadora, estudantes estagiárias e estudantes da educação básica passaram. A constatação de que a leitura nos escritos das escritoras negras e a sugestão de produzir outros trabalhos provocaram mudanças de atitudes em todos/as envolvidos/as na atividade pedagógica extensionista.

Também vale destacar, que esse trabalho serve assim, como possibilidade para adentrar nas discussões complexas e desdobramentos diversos no tema estudado É um trabalho que está iniciando com leitor/as/escritoras negras, com a pretensão de refletir na tomada de atitudes antirracistas, principalmente, para atingir uma postura ética e de existência de si. É evidente, que há muito que discutir e aprimorar essa ação aqui apresentada. Assim como ocorre com a leitura, o trabalho não é fechado e tem grandes desafios para encabeçar numa proposta mais desafiadora.

\section{CONSIDERAÇÕES FINAIS, PARA ESSE MOMENTO}

Ao término de um estudo referenciado na literatura de escritoras negras, em que elas falam por elas, quer pela sua raça, quer pelo gênero. (No caso das alunas/estagiárias negras em formação inicial), já chegam nos espaços escolares, da educação básica, legitimando suas relações entre educação e interseccionalidades de gênero e raça/cor. Através do poema de Elizandra Souza, teoria e ficção se interseccionam para expandir na subjetividade feminina e política, da mulher negra, na desautorização de uma identidade pensada para sujeitos periféricos, acomodados a opressão das matrizes dominantes. Elizandra parte de uma formação identitária que atravessa os enquadramentos e se estende para uma subjetividade de existência, de lugar de fala. Essa autonomia é visibilizada nos seus escritos versalizados e historicizados no poema Violação.

O objetivo de estudo foi a mulher negra na sua visibilidade pela perspectiva dos estudos pós-críticos, mais especificamente, no poema de Elizandra Souza, em que argumenta teórica e politicamente o lugar de fala da mulher negra, na sua existência, na quebra de rótulos de não escuta que foi preponderante dentro de uma visão patriarcal.

A obra de Djamila e Akotirene, da Coleção Feminismos Plurais, serviram para sustentar a análise do poema de Elizandra Souza, nos deram a possibilidade de trazer para o estudo a face do que é viver por muitos anos, sob o olhar de uma narrativa 
dominante, mas que se quebra em outros olhares, para brandir nas artimanhas de narrativas discursivas vivenciadas por mulheres negras.

Como o poema da mulher/escritora, a literatura negra exterioriza vozes plurais para a mudança de atitude e pensamento, a respeito do lugar de existência das mulheres negras, nas suas experiências e histórias de vida. $E$ isso, retrata-se nos seus escritos, haja visto, a presença feminina que resiste e cria movimento de força e superação nas suas produções escritas.

Num entrecruzamento de ideias da professora/pesquisadora e das alunas/estagiárias, de fato, desconstrói muitos territórios engendrados num sistema de dominação- o racismo. E isso é claro, vem a incerteza, dos desafios que incide nas experiências da professora/pesquisadora e na formação inicial das alunas/estagiárias.

\section{REFERÊNCIAS}

AKOTIRENE, Carla. Interseccionalidade. São Paulo: Sueli Carneiro; Pólen,2019. ALMEIDA, Silvio. Racismo Estrutural. São Paulo: Sueli Carneiro; Pólen,2019.

COLLINS, Patricia Hill. Aprendendo com a outsider within: a significação sociológica do pensamento feminista negro. Revista Sociedade e Estado, v.1, n. 99-127.p, 2016.

HOOKS, bell. Luta de Classes Feminista. Disponível em:

$<$ https://www.cabn.libertar.org/wpcontent/uploads/2013/08/LutadeClassesFeminista. pdf>. Acesso em: 15/11/2018.

MBEMBE, Achille. Crítica da razão negra. São Paulo:N-1,2018, p.175.

RIBEIRO, Djamila. Lugar de Fala. São Paulo: Sueli Carneiro; Pólen, 2019, marginal. 2014

http://www.ucs.br/etc/revistas/index.php/antares/article/viewFile/3059/1814. Acesso em: 02/10/2017.

RIBEIRO, Djamila. Pequeno Manual Antirracista.1 $1^{a}-e d$, São Paulo: Companhia das Letras; 2019.

RIBEIRO, Djamila. Quem tem medo do feminismo negro? $1^{a}$ ed. - São Paulo: Companhia das Letras, 2018.

SILVA, Ana Lúcia Gomes da. Profissão docente na Educação Básica no Piemonte da Diamantina: cartografias em construção. [prelo].

SOARES, Sergei. A demografia da cor: a composição da população brasileira de 1890 a 2007. In: THEODORO, M. (Org.) As políticas públicas e a desigualdade racial no Brasil:120 anos após a abolição. Brasília, DF: Ipea, 2008. p. 97-117.

SOUZA, Elizandra. Águas da cabeça. São Paulo: Edição do autor, 2012. 
Revista Brasileira da Educação Profissional e Tecnológica, v. 1, n. 20, e10907, 2021, p. 14 de 14 CC BY 4.0 | ISSN 2447-1801 | DOI: https://doi.org/10.15628/rbept.2021.10907

ZINANI, Cecil Jeanine Albert. Produção literária feminina: um caso de literatura Marginal.2014.Disponível em:

http://www.ucs.br/etc/revistas/index.php/antares/article/viewFile/3059/1814. 